Edith Cowan University

Research Online

Research outputs pre 2011

$1-1-2010$

\title{
The Impact of Nurses on Patient Morbidity and Mortality - the Need for a Policy Change in Response to the Nursing Shortage
}

Diane Twigg

Edith Cowan University

Christine Duffield

Peter L. Thompson

Pat Rapley

Follow this and additional works at: https://ro.ecu.edu.au/ecuworks

Part of the Nursing Commons

10.1071/AH08668

This is an Author's Accepted Manuscript of: Twigg, D. E., Duffield, C. M., Thompson, P., \& Rapley, P. (2010). The impact of nurses on patient morbidity and mortality - the need for a policy change in response to the nursing shortage. Australian Health Review, 34(3), 312 -316. Available here

This Journal Article is posted at Research Online.

https://ro.ecu.edu.au/ecuworks/6241 
The impact of nurses on patient morbidity and mortality - the need for a policy change in response to the nursing shortage

1,2

Di Twigg ${ }^{1,2}$ RN, RM, BHlthSc(Nsg)(Hons), MBA, PhD, FRCNA, FACHSE, Professor, Head of School (School of Nursing, Midwifery and Postgraduate Medicine)

Christine Duffield ${ }^{3,8}$ RN, DipNEd, BScN, MHP, PhD, Professor, Associate Dean (Research) (Acting), Director (Centre for Health Services Management), Deputy Director (WHO CC)

Peter L. Thompson ${ }^{4,5,6}$ AM, MD, MBBS, FRACP, FACC, FACP, DIPL ABIM, Clinical Professor, Deputy Director (WAIMR), Cardiologist in Charge of Coronary Care

Pat Rapley ${ }^{2,7}$ MAppSc, BSc, DipNEd, RN, FRCNA, PhD, Senior Lecturer (School of Nursing and Midwifery), Nursing Research Consultant (Centre for Nursing Research, Innovation and Quality)

School of Nursing, Midwifery and Postgraduate Medicine, Edith Cowan University, Joondalup, WA 6027, Australia.

2

Centre for Nursing Research, Innovation and Quality, Sir Charles Gairdner Hospital, Nedlands, WA 6009, Australia.

Centre for Health Services Management, Faculty of Nursing, Midwifery and Health, and World Health Organization Collaborating Centre for Nursing, Midwifery and Health Development (WHO CC), University of Technology, Sydney, Ultimo, NSW 2007, Australia. School of Medicine and Pharmacology, The University of Western Australia, Crawley, WA 6009, Australia.

5 West Australian Institute of Medical Research (WAIMR), Nedlands Campus, QEII Medical Centre, Nedlands, WA 6009, Australia.

6

Sir Charles Gairdner Hospital, Nedlands, WA 6009, Australia.

'School of Nursing and Midwifery, Curtin University of Technology, Bentley, WA 6102, Australia.

\section{Abstract}

Context. Workforce projections indicate that by 2012 there will be a shortfall of 61000 registered nurses in Australia. There is a growing body of evidence that links registered nurse staffing to better patient outcomes.

Purpose. This article provides a comprehensive review of the research linking nurse staf fing to patient outcomes at a time of growing shortages, highlighting that a policy response based on substituting registered nurses with lower skilled workers may have adverse effects on patient outcomes.

Method. An electronic search of articles published in English using the Cumulative Index to Nursing and Allied Health Literature (CINAHL), Journals @ OVID and Medline was undertaken.

Findings. Robust evidence exists nationally and internationally that links nurse staffing to patient outcomes. Recent meta-analyses have found that there was a $3-12 \%$ reduction in adverse outcomes and a $16 \%$ reduction in the risk of mortality in surgical patients with higher registered nurse staffing. Evidence confirms that improvements in nurse staffing is a cost-effective investment for the health system but this is not fully appreciated by health policy advisors.

Conclusions. An appropriate policy response demands that the evidence that patient safety is linked to nurse staffing be recognised. Policy makers must ensure there are suf ficient registered nurses to guarantee patient safety.

\section{What is known about the topic?}

Projections indicate that by 2012 there will be an estimated shortfall of 61000 registered nurses in Australia. However, research demonstrates the number of registered nurses caring for patients is critically important to 
prevent adverse patient outcomes. Evidence also corfirms that improvements in nurse staffing is a cost -effective investment for the health system.

What this paper adds? The paper exposes the lack of an appropriate policy response to the evidence in regard to nurse staffing and patient outcomes. It argues that patient safety must be recognised as a shared responsibility between policy makers and the nursing profession.

What are the implications for practitioners? Policy makers, health departments, Chief Executives and Nurse Leaders need to ensure that adequate nurse staffing includes a high proportion of registered nurses to prevent

\section{Introduction}

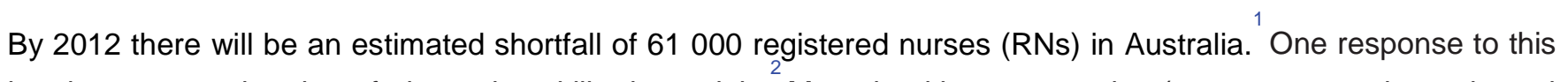
has been an exploration of alternative skill mix models. Many healthcare agencies (acute, community and aged care facilities) have changed the mix of nurses, hiring more enrolled nurses and unregulated workers (assistants in nursing or healthcare assistants) and less RNs. However, these initiatives conflict with the growing body of evidence that links the role of RNs to patient outcomes, referred to as 'nursing sensitive outcomes'. 'This paper will review the literature in regard to the relationship between the number and mix of nurses and patient outcomes including mortality. Further, the review will establish the affordability of increases in the RN workforce and discuss the lack of understanding of this critical evidence by executives and doctors. Lastly, using the outcomes of the review the authors will expose a lack of a collective policy response in Australia to the evidence in the literature.

\section{Method}

For the literature review an electronic search was undertaken of articles published in English using the Cumulative Index to Nursing and Allied Health Literature (CINAHL), Journals @ OVID and Medline dated from 1982 to 2005. A search for works by prominent authors in tfield was also undertaken. The listed search terms from these publications also assisted in establishing search terms. Search terms included outcomes (healthcare), hospital mortality, personnel stafing, skill mix, nurse -patient ratio, workload, workload measurement, educational status, practice environment, patient clasisiation methods and patient dependency. Once the initial search was undertaken, automatic weekly alerts were established to capture new publications using these search terms and key authors.

\section{Nurse staffing and patient outcomes}

A seminal study conducted two decades ago found that interaction and coordination amongst clinicians (medical and nursing staff) reduced patient deaths in ICU settings, but did not establish a link between nursing activities and patient outcomes. Since then a growing body of research indicates that RNs provide a continuous (24-h per day, 7 days per week) surveillance system for patients enabling the early detection and prompt intervention when their condition deteriorates. Nurses are in the best position to initiate actions that minimise adverse events and negative outcomes for patients. The effectiveness of nurse surveillance is thuenced by the number and mix of nurses available to assess patients on an ongoing basis. In seminal work Needleman et al.

(p. xxiii) have identified several 'outcomes potentially sensitive to nursing (OPSN)', which they defined as:

a group of patient complications that had been established in the literature, which include urinary tract infections, skin pressure ulcers, hospital acquired pneumonia, and deep vein thrombosis or pulmonary embolism; a group of exploratory measures, comprised of upper gastrointestinal bleeding, central nervous system complications, sepsis, and shock or cardiac arrest; complications among surgical patients only, which included surgical wound infection, pulmonary failure, and metabolic derangement, and a final group consisting of mortality, two different measures of patient length of stay and failure to rescue, which was constructed as a death among patients with shock, sepsis, pneumonia, deep vein thrombosis or pulmonary embolism or gastrointestinal bleeding.

One example of how these outcomes relate to nursing can be found with hospital-acquired pneumonia, where two key risk factors are prolonged immobility, which leads to inadequate ventilation of parts of the lungs, and inappropriate or failure to perform pulmonary hygienic techniques. Nursing care influences both risk factors. More commonly now these patient outcomes are referred to as nursing (or nurse) sensitive outcomes. A great deal of research has been conducted linking a variety of nursing and staf fing factors related to these outcomes: a summary follows.

\section{The relationship between nurse staffing and patient outcomes}

Early work established that higher levels of RN staffing, measured as RN hours per inpatient-day, were associated with improved patient outcomes. ${ }^{8-15}$ These included urinary tract infections and pneumonia after major surgery, 
thrombosis and pulmonary compromise in surgical patients, ${ }_{10,11}^{9}$ pneumonia in elective and emergency patients, medication errors, pressure ulcers and patient complaints, mortality rates and nosocomial infection rates. Other positive outcomes included better functional health outcomes, pain management and patients' perceptions of nursing care at discharge.

The results strongly suggested that increased RN-to-patient ratios were inversely related to mortality rates; an increase in mean length of stay occurred with decreased staffing ratios; and higher staffing by RNs was associated with lower rates of unit-specific complications. ${ }^{12,15}$ However, there were several methodological concerns raised with respect to this early work. Many studies were undertaken at only one hospital or a small number and range of units, resulting in small sample sizes and ambiguity over what constituted patient outcomes.

Two landmark studies involving large administrative datasets provided more robust evidence and addressed many of the concerns identified above. The first study ${ }^{7}$ utilised discharge abstracts from 799 hospitals in 11 states of the USA, providing a much larger sample size than any previous study. A second study used discharge data from over 200000 patients at 168 adult general hospitals in Pennsylvania. Both studies found that lower RN stafng levels adversely affected patient outcomes. In these studies 'failure to rescue' was a term used to describe a death from the complication of pneumonia, shock or cardiac arrest, upper gastrointestinal bleeding, sepsis or deep vein thrombosis. Needleman et al. found that a higher proportion of hours of care per day and the absolute hours of care provided by RNs were associated with a shorter length of stay, fewer urinary tract infections, less gastrointestinal bleeding, lower rates of pneumonia, shock or cardiac arrest and lower rates of failure to rescue in medical patients. In surgical patients, a higher proportion of care provided by RNs was linked with less urinary tract infections, and a greater number of hours of care per day provided by RNs was linked with lower rates of failure to rescue. Aiken et al. found that each additional patient added to a nurse's workload was

associated with a $7 \%$ increase in the likelihood of dying within 30 days of admission and a $7 \%$ increase in the likelihood of failure to rescue (the results were risk adjusted for patient and hospital characteristics). Both studies concluded that substantial decreases in mortality rates would occur if there were increased RN staffing.

This growing body of evidence was initially dismissed at a policy level internationally as the work was conducted in the United States where the care system was different from most other industrialised countries. However, since that time, similar large scale studies conducted in England, Canada ${ }^{17,18}$ and Australia have demonstrated similar relationships.

The Canadian study ${ }^{17}$ found mortality rates from 18142 patients in 49 acute care hospitals in Alberta varied significantly across hospitals. Age and patient co-morbidities explained $44.2 \%$ of the variation whereas four nursing factors explained a further $36.9 \%$. The first of these nursing factors was the level of nurse education. Hospitals with a higher proportion of baccalaureate-prepared (4 year degree) nurses had lower rates of 30-day mortality, also consistent with Aiken'sfindings. ${ }^{6}$ The second factor was skill mix: Hospitals with a higher proportion of RNs had lower rates of 30-day mortality. The third factor was employment status: Hospitals with a higher proportion of casual and temporary nurses were associated with higher rates of 30-day mortality. The fourth factor was nurse-physician relationships: Hospitals with higher scores on collaborative nurse-physician relationships had lower rates of 30-day patient mortality. More recently, Tourangeau et al. have found that higher percentages of RNs, higher percentages of baccalaureate-prepared nurses, more nurses reporting adequacy of staffing and resources were also associated with lower 30-day mortality rates in medical patients.

A UK study ${ }^{16}$ that involved 30 acute care trusts, also found consistently better outcomes for patients in hospitals that had higher nurse-to-patient ratios compared to those with less favour-able staffing. The patients in better staffed hospitals had lower rates of surgical mortality and failure to rescue. Patients in hospitals with the lowest nurse-to-patient ratios had a 26\% higher mortality. The authors calculated 246 fewer deaths would have occurred in the subset of surgical patients if all patients were treated in hospitals with the most favourable nurse staf fing levels. The only Australian studies to examine the relationship between nursing hours of care and the proportion of hours of care provided by RNs found similar results. Hospitals that had a skill mix with a higher proportion of RN hours produced statistically significant decreased rates of decubitus ulcers, gastrointestinal bleeding, sepsis, shock, physiologic or metabolic derangement, pulmonary failure, failure to rescue and falls. These same authors found in a parallel study ${ }^{20}$ that increasing RN hours by $10 \%$ decreased the following adverse events central nervous system complications (45\%), gastrointestinal bleeding (37\%), urinary tract infections (34\%), failure to rescue (27\%), decubitus ulcers (19\%), sepsis (15\%) and pneumonia (11\%).

In addition to these country specific studies, several systematic reviews of the literature have recently been undertaken, each reporting similafindings. Stanton ${ }^{21}$ concluded that there was a 3-12\% reduction in adverse outcomes (falls, urinary tract infections, upper gastrointestinal bleeding, pressure ulcers, pneumonia, failure to rescue, and nosocomial infections) with higher RN staf fing levels. A second review concluded that increased patient 
mortality, failure to rescue, respiratory tract infection and decreased quality of care were significantly related to high nursing workload. ${ }^{22}$ By contrast, increased total hours of nursing time were associated with improvements in patient outcomes such as lower pressure ulcer rates, lower mortality rates, fewer medication errors, reduced length of stay, as well as reductions in the incidence of injuries and falls. Finally, Kane et al. summarised evidence that concluded that higher RN-to-patient ratios were associated with reduced mortality, failure to rescue and length of stay. Furthermore, Kane et al. found that every additional RN Full Time Equivalent (FTE) per patient-day was associated with a $16 \%$ reduced risk of mortality in surgical patients. Conversely, every additional patient-to-RN per shift was associated with a $7 \%$ increase in pneumonia, a $53 \%$ increase in pulmonary failure and a $17 \%$ increase in medical complications. In contrast, the death rate decreased by $1.98 \%$ for every additional nurse-hour per patient-day.

In summary, as the body of knowledge about nursing sensitive patient outcomes has expanded there can be no doubt the hours of care and skill mix (hours of care provided by RNs) do affect patient outcomes. Increased nursing hours and more hours of care provided by RNs have been shown to decrease patient mortality and adverse patient outcomes.

\section{Affordability of additional RN staffing}

Although the evidence strongly supported the link between an increase in nurse stafing and a higher proportion of RNs to improvements in the quality of care, questions arose as to whether or not these staffing models were affordable. In response, Needleman et al. ${ }^{23}$ utilised data from 799 hospitals to argue a business and social case for investing in nurse staffing. They analysed the costs of increasing nurse staffing to the 75th percentile for hospitals below this level to determine cost savings achieved by reduced length of stay and decreased adverse outcomes. The authors estimated from the data that increased nurse fitag could avoid 6700 inpatient hospital patient deaths; three-quarters of those from a richer RN mix, which also resulted in significant cost savings.

A second report based on Michigan (USA) data suggested that reducing the number of adverse outcomes by increasing nurse to patient ratios resulted in sigiciant savings. For example, estimate d savings of US\$22.03 million per year for Michigan hospitals related to prevention of pneumonia and US\$5.8 million per year related to nosocomial infections were possible. ${ }^{24}$ Data were also used to model the impact of sfigfg changes on patient outcomes. The estimated savings in adverse patient outcomes in a typical 200-bed hospital that moved from a 1-to-5 nurse-topatient ratio over a 10-year period to a 1-to-4 ratio was US\$7.5 million in the first year and more than

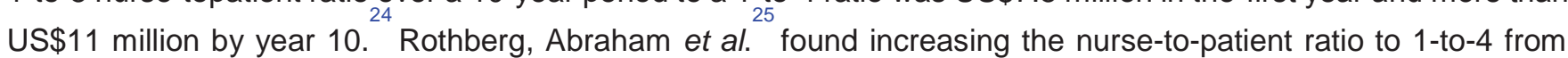
1-to-8 would save additional lives at a cost of US\$136 000 per life saved. This constituted a considerable saving compared to the cost of thrombolytic therapy in acute myocardial infarction at US\$182 000 per life saved or routine cervical cancer screening at a cost of US\$432 000 per life saved. Similarly, Cho has found the costs of hospital-acquired pneumonia to be US\$22 390-\$28 505 per episode. These

studies ${ }^{23-26}$ clearly support the proposition that to increase RN hours of care is cost effective as it improves patient outcomes but is also affordable.

\section{Understanding of the evidence by doctors and hospital executives}

Although research indicates that employment of an adequate number and mix of RNs achieves better patient outcomes and is cost effective, the importance of nurse staffing to patient outcomes is not readily understood by medical staff or chief executive officers. In a national US survey of RNs, physicians and hospital executives, significantly fewer physicians and chief executive officers than RNs believed the nursing shortage had an adverse impact on patient safety, early detection of patient complications or time for team collaboration. Twice as many RNs as physicians thought that the shortage of nurses had adversely affected patient safety. The majority of RNs and chief nursing officers expressed concern about the impact of shortages on the early detection of patient complications and nurses' ability to maintain patient safety. The majority of chief executive officers and physicians did not share this view, suggesting that chief executive officers and medical staff do not associate nurses and their work with patient safety. In addition, they did not appreciate the impact nurses had in detecting complications or rescuing the patient before their condition deteriorated and their lives were put at risk. Although similar studies have not been conducted in Australia, there is no reason to think views would be starkly different to these. The safety of hospital patients remains a shared responsibility amongst the health professions and as the views of senior clinical staff and chief executive officers influence health policy, it is essential that informed decisions are made, decisions based on the evidence.

\section{Workforce shortages}

A further challenge in providing adequate nurse stafing and a richer RN mix is the nursing shortage. Workforce projections in Australia, particularly for nursing, are grim. In 2000 an estimated 170000 new people entered the workforce per annum but by 2020 this number is expected to drop to 12500 per annum and there will be an 
estimated shortfall of 61000 nurses. Although demand is growing the current supply is just meeting replacement needs. Of equal concern is that the nursing workforce is aging more rapidly than others with the average age rising from 42.2 in 2001 to 45.1 years in 2005 . The proportion of nurses aged 50 years and older increased from 24.4 to $35.8 \%$. Consequently, over the next decade more than one third of the Australian nursing workforce is likely to retire. These trends indicate Australian heath care services will face siginiant challenges in se curing adequate nursing resources (both hours of care and RN skill mix) to provide safe and effective patient care. In part these shortages have been exacerbated because RNs perceive their workload has increased as the skill mix has changed, leading to a greater likelihood of them leaving.

\section{Policy response}

The demonstrated relationship between nurse staffing, and in particular the role of RNs in improving patient outcomes, requires a collaborative policy response to not only increase the number of nurses in the workforce but more importantly, to increase the proportion of RNs employed. However, the reality is that the exact opposite is occurring. Calls for greater workforceflexibility and skill mix changes have resulted in substitution of more highly skilled workers with assistant type roles ${ }^{6}$ rather than maximising use of the skills and expertise of the RN workforce to enhance patient safety. This workforce trend has overlooked the evidence supporting improved patient outcomes when health services have more hours of care provided by RNs. In addition, the number and diversity of key players at both state and federal levels involved in workforce planning, education, training and accreditation make it difficult to achieve a coordinated policy response. This diversity of stakeholders results in fragmentation of responsibilities, ineffective coordination between sectors and ineficiencies in funding and payment arrangements. Effective and efficient policy responses in this climate are difficult, for example coordination of the number of university places made available for nurse education.

If governments are serious about reducing the number of patient deaths, then government policy should focus on initiatives aimed at maximising the number of RNs at patients' bedsides. Current thinking about new models of care that maximise the use of less skilled workers to assist in patient care is not congruent with evidence to hand. RNs are a critical part of the healthcare team and the number of RNs in the team is directly linked to patient safety. Policy responses should also support the determination of safe levels of nurse staffing, including the mix of nurses, by funding studies to empirically examine specific nurse staffing methods. Recently in New Zealand a component of the national multi-employer collective agreement ${ }^{33}$ was to establish a safe staf fing commission to assess the impact and implications of low steffng levels, nursing workload, and to create guidelines on safe staffing and healthy workplaces. Addressing the global nursing shortage crisis requires partnerships involving all sectors, actively engaging stakeholders to implement, monitor and evaluate effective policy interventions and strategies to attract and retain nurses, especially RNs, into the health workforce. In Australia, the Australian Commission on Safety and Quality in Health Care recently published a proposed list of 58 indicators by which hospital performance would be assessed. Unlike the United States, nursing skill mix was not one of the indicators.

In conclusion, this paper has highlighted the important role of nurses in providing a continuous surveillance system enabling the early detection and prompt intervention when patients' conditions deteriorate. The ability of nurses to initiate actions that minimise adverse events and negative outcomes for patients is directly linked to the hours of care and the skill mix (proportion of RN hours worked) and has been shown to be cost effective and affordable.

Although Australia is facing significant nursing shortages that are predicted to worsen over the coming decade, the policy response to the nursing workforce shortages to date have been inadequate. Strategies relying on substitution with less skilled workers ${ }^{2,35}$ is in direct contrast to the evidence.

\section{Competing interests}

No conflicts of interest exist.

\section{Acknowledgements}

Prof D. Twigg was awarded the Western Australian Nurses Memorial patient safety. Centre for Health Services Management, University of Charitable Trust Grant of AU\$19 613.

\section{References}

1 Access Economics. Employment Demand in Nursing Occupations. Canberra: Department of Health \& Ageing; 2004.

2 Productivity Commission. Australia's Health Workforce: Research Report. Canberra; 2005.

3 Kane RL, Shamliyan T, Mueller C, Duval S, Wilt T. Nursing \$tex and Quality of Patient Care. Evidence Report/Technology Assessment No. 151 (Prepared by the Minnesota Evidence based Practice Center under 
Contract No. 290-02-0009). Rockville, MD: Agency for Healthcare Research and Quality; 2007. Available at http://www.ahrq. gov/downloads/pub/evidence/pdf/nursestaff/nursestaff.pdf [verifed 11 April 2008].

4 Knaus WA, Draper EA, Wagner DP, Zimmerman JE. An evaluation of outcome from intensive care in major medical centers. Ann Intern Med 1986; 104(3): 410-8.

5 Aiken LH, Clarke SP, Sloane DM, Sochalski J, Silber JH. Hospital nurse sfizfg and patient mortality, nurse burnout, and job dissatisfaction. JAMA 2002; 288(16): 1987-93. doi:10.1001/jama.288.16.1987

6 Aiken LH, Clarke SP, Cheung RB, Sloane DM, Silber JH. Educational levels of hospital nurses and surgical patient mortality. JAMA 2003; 290(12): 1617-23. doi:10.1001/jama.290.12.1617

7 Needleman J, Buerhaus P, Mattke S, Stewart M, Zelevinsky K. Nurse-staffing levels and the quality of care in hospitals. N Engl J Med 2002; 346(22): 1715-22. doi:10.1056/NEJMsa012247

8 Kovner C, Jones C, Zhan C, Gergen PJ, Basu J. Nurse staf fing and post surgical adverse events: an analysis of administrative data from a sample of US hospitals 1990-1996. Health Serv Res 2002; 37(3): 611-29.

9 Kovner C, Gergen P. Nurse stafing and adverse events following surgery in US hospitals. Image J Nurs Sch 1998; 30(4): 315-21. doi:10.1111/j.1547-5069.1998.tb01326.x

10 Blegen MA, Goode CJ, Reed L. Nurse staffing and patient outcomes. Nurs Res 1998; 47(1): $43-50$. doi:10.1097/00006199-199801000-00008

11 Blegen MA, Vaughn T. A multisite study of nurse sfiag and patient occurrences. Nurs Econ 1998; 16(4): 196-203.

12 Schultz MA, van Servellen G, Chang BL, McNeese-Smith D, Waxenberg

E. The relationship of hospital structural andnancial characteristics to mortality and length of stay in acute myocardial infarction patients. Outcomes Manag Nurs Pract 1998; 2(3): 130-6.

13 Seago JA. Nurse stafing, models of care delivery, and interventions. Rockville, MD: Agency for Healthcare Research and Quality; 2001. Available at http://www.ahrq.gov/clinic/ptsafety/index.html\#toc [verified 11 June 2008].

14 McGillis Hall L, Doran D, Baker GR, Pink GH, Sidani S, O'Brien-Pallas L, Donner GJ. Nurse staffing models as predictors of patient outcomes. Med Care 2003; 41(9): 1096-109. doi:10.1097/01.MLR.0000084180. 07121.2B

15 Heinz D. Hospital nurse stafing and patient outcomes: a review of current literature. Dimens Crit Care Nurs 2004; 23(1): 44-50. doi:10.1097/00003465-200401000-00011

16 Rafferty AM, Clarke SP, Coles J, Ball J, James P, McKee M, Aiken LH. Outcomes of variation in hospital nurse staffing in English hospitals: cross-sectional analysis of survey data and discharge records. Int J Nurs Stud 2007; 44(2): 175-82. doi:10.1016/j.ijnurstu.2006.08.003

17 Estabrooks CA, Midodzi WK, Cummings GG, Ricker KL, Giovannetti P. The impact of hospital nursing characteristics on 30-day mortality. Nurs Res 2005; 54(2): 74-84. doi:10.1097/00006199-200503000-00002

18 Tourangeau AE, Doran DM, McGillis Hall L, O'Brien-Pallas L, Pringle D, Tu JV, Cranley LA. Impact of hospital nursing care on 30-day mortality for acute medical patients. J Adv Nurs 2006; 57(1): 32-44. doi:10.1111/j.1365-2648.2006.04084.x

19 Duffield C, Roche M, O'Brien-Pallas L, Diers D, Aisbett C, King M, Aisbett K, Hall J. Glueing it together: nurses, their work environment and Technology, Sydney 2007. Available at http://www.health.nsw.gov.au/ pubs/2007/pdf/utsreport_final.pdf [verified 11 June 2008].

20 Duffield C, Roche $\bar{M}$, O'Brien-Pallas L, Diers D, Aisbett C, Aisbett K, Homer C. Nursing workload and staffing: impact on patients and staff. Centre for Health Services Management, University of Technology, Sydney; 2009.

21 Stanton MW. Hospital nurse stafing and quality of care. US Department of Health \& Human Services; 2004. Available at http://www.ahrq.gov/ research/nursestaffing/nursestaff.htm [verified 11 June 2008].

22 Pearson A, O'Brien-Pallas LL, Thomson D, Doucette E, Tucker D, Wiechula RJ, Long LE, Porritt KA, Jordan ZL. Systematic review of evidence on the impact of nursing workload and staf fing on establishing healthy work environments. Journal of Evidence Based Healthcare 2006; 4: 337-84.

23 Needleman J, Buerhaus P, Stewart M, Zelevinsky K, Mattke S. Nurse stafing in hospitals: is there a business case for quality? Health Aff 2006; 25(1): 204-11. doi:10.1377/hlthaff.25.1.204

24 Michigan Nurses Association. The model case for reducing patient-tonurse ratios in Michigan hospitals: two scenarios. Lansing, MI: Public Policy Associates, Incorporated; 2004.

25 Rothberg MB, Abraham I, Lindenauer PK, Rose DN. Improving nurseto-patient staffing ratios as a cost-effective safety intervention. Med Care 2005; 43(8): 785-91. doi:10.1097/01.mlr.0000170408.35854.fa

26 Cho SH, Keteian S, Barkauskas VH, Smith DG. The effects of nurse staffing on adverse events, morbidity, mortality, and medical costs. Nurs Res 2003; 52(2): 71-9. doi:10.1097/00006199-200303000-00003

27 Buerhaus P, Donelan K, Ulrich BT, Norman L, DesRoches C, Dittus R. Impact of the nurse shortage on hospital patient care: comparative perspectives. Health Aff 2007; 26(3): 853-62. doi:10.1377/hlthaff.26.3.853

28 Access Economics. Population ageing and the Economy. Canberra: Department of Aged Care; 2001. Available at http://www.accesseconomics. com.au/publicationsreports/showreport. php?id=49\&searchfor=2002\& searchby=yearearlier [verified 6 June 2008].

29 Letvak S. Myths and realities of ageism and nursing. AORN Journal 2002; 75(6): 1101-7.

30 Australian Institute of Health and Welfare. Nursing and Midwifery Labour Force 2005. Canberra: AlHW; 2008.

31 Duffield C, O'Brien-Pallas L. The causes and consequences of nursing shortages: a helicopter view of the research. Aust Health Rev 2003; 26(1): 186-93. doi:10.1071/AH030186

32 Tourangeau AE, Cranley LA, Jeffs L. Impact of nursing on hospital patient mortality: a focused review and related 
policy implications. Qual Saf Health Care 2006; 15(1): 4-8. doi:10.1136/qshc.2005.014514

33 New Zealand Nurses Organisation. District Health Boards/NZNO multi-employer nursing/midwifery collective agreement 1 July 2004-31 December 2006. Wellington: New Zealand Nurses Organisation; 2004. Available at http://www.lakesdhb.govt.nz/Resource.aspx?ID=779 [verified 31 May 2009].

34 Australian Institute for Health and Welfare. Towards national indicators of safety and quality in health care. Discussion Paper. Canberra: AlHW; 2008.

35 BuchanJ,CalmanL.OEDCHealthWorkingPapersNo.17:Skillmixand policy changes in the health workforce: nurses in advanced roles. Paris: Publication Services OEDC; 2005. 